University of Nebraska - Lincoln

DigitalCommons@University of Nebraska - Lincoln

USDA National Wildlife Research Center - Staff Publications
U.S. Department of Agriculture: Animal and Plant Health Inspection Service

2011

\title{
Effects of Management on Double-Crested Cormorant Nesting Colony Fidelity
}

\author{
Bronson K. Strickland \\ USDA, APHIS, Wildlife Services, bstrickland@cfr.msstate.edu \\ Brian S. Dorr \\ USDA/APHIS/WS National Wildlife Research Center, brian.s.dorr@aphis.usda.gov \\ Fred E. Pogmore \\ USDA Wildlife Services, Fred.E.Pogmore@aphis.usda.gov \\ Gary Nohrenberg \\ USDA, APHIS, Wildlife Services \\ Scott C. Barras \\ USDA, APHIS, Wildlife Services \\ See next page for additional authors
}

Follow this and additional works at: https://digitalcommons.unl.edu/icwdm_usdanwrc

Strickland, Bronson K.; Dorr, Brian S.; Pogmore, Fred E.; Nohrenberg, Gary; Barras, Scott C.; Mcconnell, John E.; and Gobeille, John, "Effects of Management on Double-Crested Cormorant Nesting Colony Fidelity" (2011). USDA National Wildlife Research Center - Staff Publications. 1315.

https://digitalcommons.unl.edu/icwdm_usdanwrc/1315

This Article is brought to you for free and open access by the U.S. Department of Agriculture: Animal and Plant Health Inspection Service at DigitalCommons@University of Nebraska - Lincoln. It has been accepted for inclusion in USDA National Wildlife Research Center - Staff Publications by an authorized administrator of DigitalCommons@University of Nebraska - Lincoln. 
Authors

Bronson K. Strickland, Brian S. Dorr, Fred E. Pogmore, Gary Nohrenberg, Scott C. Barras, John E. Mcconnell, and John Gobeille 


\title{
Effects of Management on Double-Crested Cormorant Nesting Colony Fidelity
}

\author{
BRONSON K. STRICKLAND, ${ }^{\mathbf{1 , 2}}$ USDA, APHIS, Wildlife Services, National Wildlife Research Center, Mississippi Field Station, P.O. Box 6099, \\ Mississippi State, MS 39762, USA \\ BRIAN S. DORR, USDA, APHIS, Wildlife Services, National Wildlife Research Center, Mississippi Field Station, P.O. Box 6099, Mississippi State, \\ MS 39762, USA \\ FRED POGMORE, USDA, APHIS, Wildlife Services, 59 Chennell Drive, Suite 7, Concord, NH 03301-8548, USA \\ GARY NOHRENBERG, ${ }^{3}$ USDA, APHIS, Wildlife Services, 59 Chennell Drive, Suite 7, Concord, NH 03301-8548, USA \\ SCOTT C. BARRAS, ${ }^{4}$ USDA, APHIS, Wildlife Services, National Wildlife Research Center, Mississippi Field Station, P.O. Box 6099, \\ Mississippi State, MS 39762, USA \\ JOHN E. MCCONNELL, ${ }^{5}$ USDA, APHIS, Wildife Services, 59 Chennell Drive, Suite 7, Concord, NH 03301-8548, USA \\ JOHN GOBEILLE, Vermont Fish and Wildlife Department, 111 West St., Essex Jct., VT 05452, USA
}

\begin{abstract}
The increase of double-crested cormorant (Phalacrocorax auritus; hereafter, cormorant) populations during the last 2 decades has impacted many stakeholder groups. The negative effects of nesting cormorants on trees and other vegetation have motivated private organizations and government agencies to manage nesting colonies and reduce their impacts to private property and public resources. Managementinduced reproductive failure has been shown to influence cormorant inter-annual nesting colony fidelity, but not complete abandonment from a nesting colony site. We attached very high frequency (VHF) transmitters and Global Positioning System (GPS) transmitters to nesting cormorants to monitor their movement response on a managed site (Young Island, VT [YI]) and an unmanaged site (Four Brothers Islands, NY $[\mathrm{FB}])$. Additionally, we monitored these sites to determine the influence of management activities on subsequent-year colonization. On YI, management consisted of egg-oiling all cormorant nests (some nests had been oiled in previous years) and culling approximately $20 \%$ of adults. Annual dispersal rates did not differ between managed and unmanaged sites, but a nesting period interaction occurred with greater dispersal on the managed site following the incubation period. After 4 years of both egg oiling and culling, cormorant nesting on YI declined to zero. Simultaneously, cormorant numbers increased on the nearby unmanaged FB. We propose either the cumulative effect of partial or complete reproductive failure $(8 \mathrm{yr})$ or simply the inclusion of adult culling ( $4 \mathrm{yr}$ ) caused the abandonment. From a colony-specific management perspective, the rapid decline was beneficial to the goal of restoring the vegetative community on YI. The effects of adult culling at nesting colonies, prior-year reproductive failure caused by egg oiling, or the combination of these factors may be required for complete and rapid nesting site abandonment. The use of culling adult breeders reduced nesting and likely limits the cost and logistics of control and allows more rapid initiation of mitigation measures and island habitat restoration. ( 2011 The Wildlife Society.
\end{abstract}

KEY WORDS colony abandonment, culling, dispersal, double-crested cormorant, egg oiling, nesting colony fidelity, Phalacrocorax auritus, New York, Vermont.

During the last 20 years, cormorant populations have increased markedly in North America (Weseloh et al.

Received: 27 August 2009; Accepted: 13 October 2010;

Published: 4 May 2011

${ }^{1}$ E-mail: bstrickland@cfr.msstate.edu

${ }^{2}$ Present Address: Department of Wildlife, Fisheries and Aquaculture, P.O. Box 9690, Mississippi State, MS 39762, USA.

${ }^{3}$ Present Address: USDA Wildlife Services, 644 Bayfield St., Suite 215, St. Paul, MN 55107, USA.

${ }^{4}$ Present Address: USDA Wildlife Services, P.O. Box 130, Moseley, VA 23120, USA.

${ }^{5}$ Present Address: USDA, APHIS, Wildlife Services, 920 Main Campus Dr., Suite 200, Raleigh, NC 27606, USA.
1995, Glahn et al. 2000). Although this increase has been viewed as a wildlife management success, cormorants have negatively impacted fisheries resources (VanDeValk et al. 2002, Rudstam et al., 2004, Fielder 2008) and aquaculture production (Glahn and Brugger 1995, Wywialowski 1999, Glahn et al. 2002) and may be competing with other colonial birds for nesting habitat (Cuthbert et al. 2002). Unique habitats may also be impacted by cormorant nesting (Hebert et al. 2005). The combination of accumulated cormorant feces and the tendency for cormorants to strip trees of their leaves for nest material can be lethal to trees and reduce vegetation communities to those species tolerant of elevated amounts of guano (Lemmon et al. 1994, Bédard et al. 1995). These various impacts have led to widespread efforts to 
manage local cormorant populations and generated proposals for regional cormorant management programs.

Similar to the New England (Krohn et al. 1995) and Great Lakes regions (Weseloh et al. 1995), cormorant nesting populations on Lake Champlain (located on the New York and Vermont borders) have increased during the last 2 decades (Fowle et al. 1999). Cormorants began nesting on Lake Champlain in the 1980s and populations had increased to $>4,000$ breeding pairs in 2007 (Fowle et al. 1999, Duerr et al. 2007). Habitat degradation and negative perceptions of these birds by various stakeholders increased with cormorant abundance on Young Island, Vermont (YI; Daniel 1989).

Before the colonization of gulls (Larus spp.) and cormorants on YI, the island exhibited a forested vegetation community that supported many tree- and ground-nesting avian species (Daniel 1989). In the decades following the gull and cormorant colonization, the forested vegetation community was lost and replaced with non-native invasive species like bull thistle (Cirsium vulgare), stinging nettle (Urtica dioica), and lambsquarters (Chenopodium album; J. Gobeille, Vermont Fish and Wildlife Department [VFWD], personal communication). As a result, tree-nesting birds such as black-crowned night herons (Nycticorax nycticorax) are now absent on YI.

The VFWD, in cooperation with the United States Department of Agriculture's (USDA) Wildlife Services Program, endeavored to recover vegetation on YI from cormorant damage and to reduce the potential damage to vegetative plantings by reducing the number of breeding pairs of cormorants. The restoration objective is consistent with VFWD's goal to protect and encourage wildlife diversity on state-owned lands. The degree of reduction required to achieve management goals and the response of cormorants to these management strategies were unknown. Because cormorants may demonstrate high inter-annual nest-site fidelity, managing a nesting colony through egg-oiling and adult culling may eventually eliminate nesting at a particular site (Hatch and Weseloh 1999). Conversely, if cormorants seek to colonize new nesting sites each year, management efforts may serve to only harass cormorants within a year and result in a colony replete with new cormorants the following year. Since 1999, partial or complete egg oiling of cormorant nests had occurred on YI (see Duerr et al. [2007] for description of egg oiling program). However, the nesting colony was still considered to be too numerous to initiate habitat management on YI. Therefore, biologists chose an adaptive management approach to determine the cormorant response to egg oiling and culling of adults. Following issuance of a public resource depredation order by the United States Fish and Wildlife Service (2003), culling of adult cormorants was implemented on YI to further reduce nesting colony numbers. During this time, we used nest counts and radio- and satellite-telemetry techniques to determine effectiveness of the management program and to monitor the movement response of nesting cormorants to population-control techniques. We hypothesized that population-control techniques would increase the within- year dispersal of cormorants from YI and cause interannual decline in nesting-colony numbers.

\section{STUDY AREA}

We conducted our study on Lake Champlain, located on the borders of New York and Vermont, USA (Fig. 1). Young Island (YI; 44 $44^{\prime} 24^{\prime \prime} \mathrm{N}, 73^{\circ} 20^{\prime} 43^{\prime \prime} \mathrm{W}$ ) was about 2 ha and was located about $31 \mathrm{~km}$ northwest of Burlington, Vermont. Four Brothers Islands (FB; $44^{\circ} 25^{\prime} 48^{\prime \prime} \mathrm{N}, 73^{\circ} 20^{\prime} 19^{\prime \prime} \mathrm{W}$ ) were comprised of 4 islands that totaled about 7 ha and were located about $2.5 \mathrm{~km}$ east of Willsboro Point, New York. The linear distance between $\mathrm{YI}$ and FB was about $34 \mathrm{~km}$. On YI, cormorants nested exclusively on the ground, whereas at FB they nested in trees and on the ground. On FB, most cormorants nested on the most western island (called Island D). Young Island was owned by the state of Vermont and managed by the VFWD. Four Brothers Islands were owned by The Nature Conservancy who decided not to manage the growing nesting colony.

\section{METHODS}

We captured cormorants on FB using padded foot-hold traps with weakened springs to minimize foot injury (King et al. 2000). Once we flushed birds from their nest, we carefully set aside the eggs and set the trap in the nest. On YI, we used a combination of foot-hold traps and hand-held nets (hoopstyle net affixed to an approx. $1.5-\mathrm{m}$ pole) to capture cormorants. We conducted all capture on YI at night to minimize egg depredation by gulls, and working at night facilitated capture of many cormorants using the nests. We used backpack harnesses (Dunstan 1972, King et al. 2000) to mark 30 cormorants on YI (3 May and 9 May) and 30 cormorants on FB ( 3 May and 11 May) in 2005, and 30 cormorants on YI (9 May) and 33 cormorants on FB (10 May) in 2006, with very high frequency (VHF) transmitters from Advanced Telemetry Systems (ATS; Isanti, MN). We programmed transmitters to run constantly for 180 days, turn off for 145 days, and then turn on again for another 180 days. We also attached United States Geological Survey metal bands and plastic color bands before releasing cormorants at the capture site. We used ATS R4500S receivers combined with ATS R2100 automated data loggers to record presence or absence of VHF-marked cormorants on nesting colonies. We placed data loggers on (YI) or adjacent to (FB) the island of capture in secure locations to optimize VHF signal reception. Data loggers scanned the cormorant VHF frequencies constantly, which resulted in an attempted frequency acquisition about every $15 \mathrm{~min}$ to $1 \mathrm{hr}$, depending on the number of frequencies acquired.

To descriptively evaluate movements outside of the breeding colonies and range of our VHF-radio data loggers, we marked some cormorants with Microwave Telemetry, Inc. (Columbia, MD) Global Positioning System (GPS), solarpowered platform transmitter terminals (PTT). We programmed the 30-g model PTT-100 transmitters to transmit once hourly and download every 3 days from the time of capture until transmission ceased. The Argos Data Collection and Locations Systems (Suitland, MD) provided 


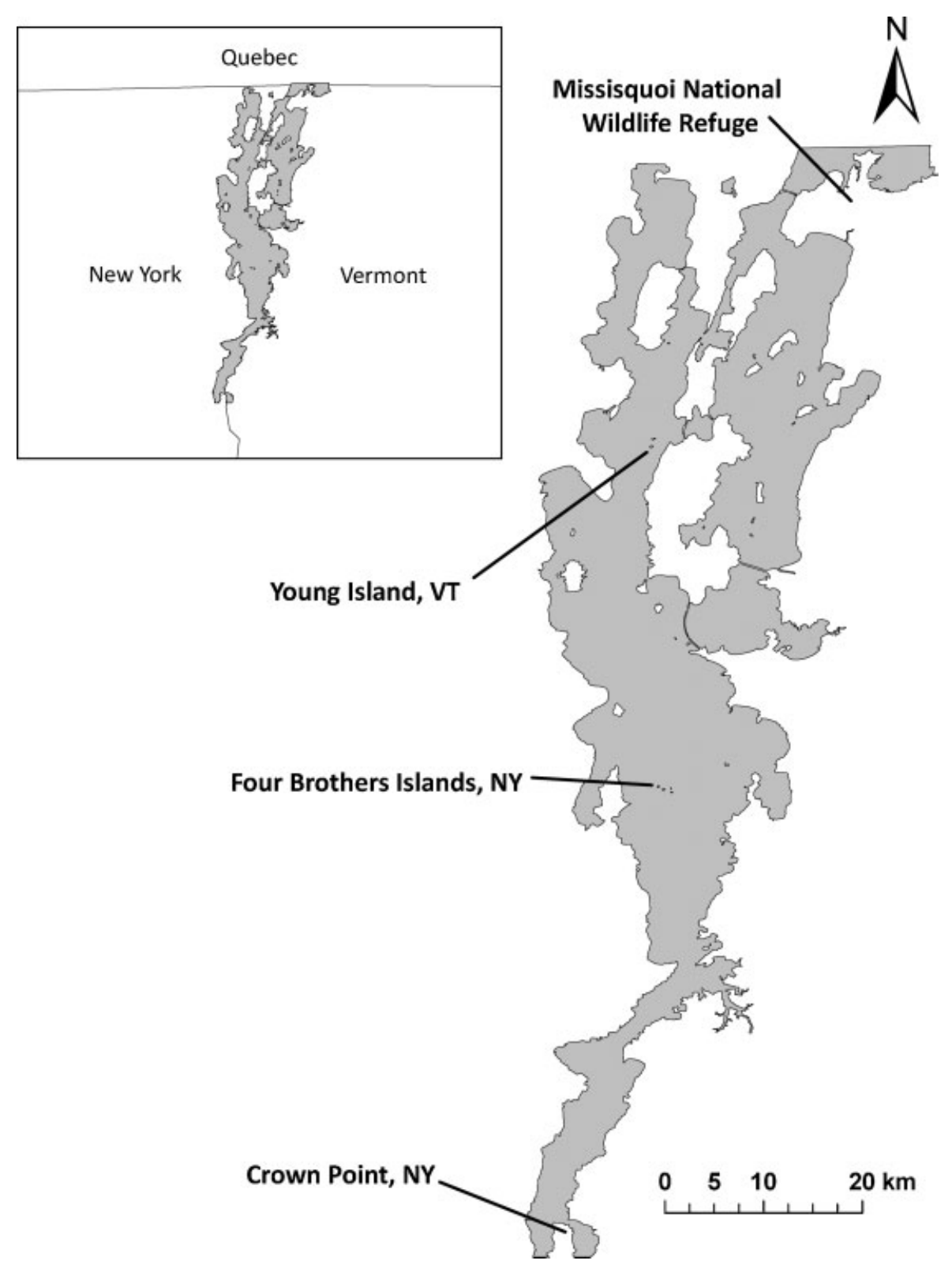

Figure 1. Study area where we monitored nesting colonies of double-crested cormorants on Young Island, Vermont and Four Brothers Islands, New York, located on Lake Champlain with radio and satellite telemetry in 2005 and 2006 to determine effects of egg oiling and adult culling on cormorant dispersal. Other nesting colonies existed previously at Missisquoi National Wildlife Refuge and Crown Point, New York, and were areas of concern during our study.

PTT location data. We marked 5 cormorants on each breeding colony in 2005 and 2006 (i.e., 10 each year) with a backpack harness as described for VHF-marked cormorants. All procedures were approved by the USDA National Wildlife Research Center's Institutional Animal Use and Care Committee in study protocol QA-1262.

\section{Cormorant Management}

We counted the number of active nests on $\mathrm{YI}$ and FB each year immediately prior to hatching to index the abundance of breeding pairs on Lake Champlain. These nest counts were the basis for determining the number of cormorants to cull annually and to gauge effects of management.

Within hours following the attachment of transmitters to cormorants on YI, we sprayed eggs in all located cormorant nests with corn oil at night. Egg oiling reduces hatching success by causing asphyxiation (Shonk et al. 2004). We returned to YI every 2-3 weeks for a total of 3 egg-oiling events each year to ensure all nests had been treated. Based on the Public Resource Depredation Order and regulatory authority of the Fish and Wildlife Service, we used a noise-suppressed .22 caliber rifle to cull $\leq 20 \%$ of adult cormorants nesting on YI each year. Culling events occurred on 9 June and 20 June in 2005 and 6 June and 15 June in 2006. Partial or complete egg oiling of cormorant nests had occurred on YI since 1999 (see Duerr et al. [2007] for greater detail of the egg-oiling program and trends in nest counts on YI and FB). Only from 2004 to 2007 did both culling and egg oiling occur. During transmitter attachment (YI and FB) and egg oiling (YI), cormorants typically abandoned their nest and loafed in peripheral waters. Cormorants returned to their nests immediately after researchers left the nesting 
vicinity. During culling events (YI) some cormorants temporarily abandoned the nesting colony while personnel set up in an old 2-story cabin, but cormorants appeared to return to the colony soon after. The cabin provided a concealed, covered vantage point for sharp-shooter(s). We assumed that culled cormorants were breeding adults because we shot them on or around active nests. We sexed a sample of cormorants to determine whether a sex-biased harvest occurred. Other than the aforementioned management activities, monthly visits to the sites to download information from the data loggers, and visits for bird band observations by other researchers and miscellaneous public visits, the sites were not disturbed.

Other than at YI and FB, cormorants have been documented nesting at the Missisquoi National Wildlife Refuge (MQNWR), Vermont, and at Crown Point, New York (Fig. 1). The VFWD and WS personnel did not allow development of new nesting colonies on Lake Champlain during our study. If VFWD or WS personnel were notified of or detected nest building in new areas, they harassed birds and destroyed nests until cormorants dispersed from the area.

\section{Data Analysis}

We evaluated nesting colony fidelity 2 ways. First, we monitored presence of VHF-marked cormorants on YI and FB between midnight and $0500 \mathrm{hr}$ (Anderson et al. 2004) to determine if cormorants that dispersed from a particular island moved to the other study site (e.g., did cormorants disperse from YI and move to FB). If we recorded a cormorant $\geq 2$ times during this period, we concluded the individual was present on the island for that particular night. We excluded daylight hours because cormorants are primarily diurnal foragers and foraging movements throughout the day made colony fidelity difficult to determine (Hatch and Weseloh 1999). Thus, we counted daily the total number of cormorants present on their capture site or on the opposing study site. We predicted that cormorants on the managed site (YI) would demonstrate greater within-year dispersal and move to $\mathrm{FB}$ more often that cormorants on the control site $(\mathrm{FB})$ would disperse to $\mathrm{YI}$.

Second, we counted the number of days each VHF-marked cormorant was present on the island of capture between midnight and $0500 \mathrm{hr}$ during 4 distinct nesting periods: incubation (9 May-7 Jun), nestling (8 Jun-5 Jul), fledgling (26 Jul-17 Aug), and post-breeding (18 Aug-18 Sep). We used the mean of 4 years of behavioral observations on both $\mathrm{YI}$ and FB to determine the start and ending dates of each period (A. Duerr, University of Vermont, unpublished data). We divided the number of days a cormorant was present during a period by the total number of days for that period to calculate the percentage of days present. For this analysis we wanted to include only cormorants that maintained residency following capture and marking. Thus, if a cormorant was not present on the island of capture $\geq 4$ days of the first week post-capture, we did not include it in this analysis. Furthermore, if VHF-marked cormorants were inadvertently culled during management activities, or were reported dead, we excluded them from analysis for the corresponding period.

With the GLIMMIX procedure in SAS (SAS Institute, Inc., Cary, NC), we used a repeated-measures logistic model to determine the influence of management on cormorant nesting colony fidelity (Littell et al. 2006). The response variable was the sum of nights we recorded a cormorant on the island of capture during the aforementioned nesting periods divided by the total number of days during a particular nesting period (we used the events/trial syntax to represent this proportion). Fixed effects were management treatment (represented by island), nesting periods, and year, and we used an autoregressive covariance structure. We conducted means comparison tests with $t$-tests. We predicted that management (egg oiling and culling) would promote greater short-term (within nesting period) and long-term dispersal (i.e., emigration from colony) on YI compared to the non-managed site (FB).

Ashmole's halo hypothesis predicts that colonial breeding bird numbers are limited by available food supplies during the breeding season, which is essentially a function of the energetic cost associated with the increased foraging distance a bird must travel as prey are depleted nearer breeding colonies (Ashmole 1963, Birt et al. 1987). Lewis et al. (2001) demonstrated a mathematical relationship between colony size and foraging distance and quality of the prey base for northern gannet (Morus bassanus) and Ridgeway et al. (2006) demonstrated similar density-dependent effects for cormorants in Lake Huron. Duerr (2007) and Duerr et al. (2007) indicated foraging habitat quality surrounding YI and FB may not be similar because fledgling rates were less and time spent forging was greater for cormorants nesting on FB. To assess a potential disparity in foraging habitat quality around the managed (YI) and control sites (FB), we tested if foraging bout duration of VHF-marked cormorants on FB was greater than for cormorants marked on YI. For this analysis we assumed when cormorants were absent from the island during daylight and twilight hours they were foraging. We used data recorded from 0500 to $2100 \mathrm{hr}$ to represent foraging from dawn until dusk on Lake Champlain during summer (Anderson et al. 2004). If a VHF-marked cormorant was present on the island, we recorded it approximately every $15 \mathrm{~min}$ (the amount of time needed by the scanning software to acquire a frequency fix), so we included data from cormorants that were not recorded on the island for $>20$ min (Anderson et al. 2004). Also, we considered absence from island $>4 \mathrm{hr}$ to not be foraging related and omitted those samples from analysis. We considered the individual cormorant as the sampling unit and calculated the mean duration of its foraging bouts from 0500 to $2100 \mathrm{hr}$ from 9 May to 17 August in 2005 and 2006. We only used cormorants with $\geq 10$ foraging bouts for an accurate portrayal of each cormorant's foraging activity. We used analysis of variance to determine if mean foraging bout duration of cormorants differed between islands or years or their interaction. We predicted that foraging bout duration would be greater at FB because a previous study on Lake Champlain demonstrated cormorant diet composition differed between 
$\mathrm{FB}$ and $\mathrm{YI}$ and cormorants foraged further from $\mathrm{FB}$ as compared to YI (Duerr 2007).

We descriptively evaluated movements of cormorants marked at each colony using GPS transmitters. We used only GPS units that transmitted through the entire breeding season (1 May-15 Jul) to evaluate movements of cormorants. We converted each bird's location to a point theme in ArcView GIS 3.2a. We used night (2200-0400 hr) locations to describe site fidelity because cormorants forage widely and may loaf at many locations diurnally. We counted the number of nights roosting on the cormorant's original capture colony and other night-roost locations. We specifically describe movements to MQNWR and the St. Lawrence River, as these locations had nesting colonies in the past and were highlighted as a concern by VFWD, MQNWR, and the Ministry of Sustainable Development, Environment and Parks, Quebec, Canada. Management-induced movements were a concern with respect to potential impacts to nesting wading birds at MQNWR and emigration to cormorant colonies in the St. Lawrence River, Quebec, Canada, specifically Lac Saint-Pierre.

\section{RESULTS}

Of the 123 cormorants marked on YI and FB with VHF transmitters in 2005 and 2006, 48 emigrated (or the transmitter failed) following radio-attachment; 14 emigrated from YI versus 34 from FB. Another 6 cormorants were shot during culling events on YI and 6 cormorants died of unknown causes (Table 1).

In both years, more cormorants exhibited fidelity at the managed YI site following capture and during the incubation period. Conversely, more cormorants dispersed immediately following capture and during the incubation period at the control site, FB (Fig. 2). However, following the incubation period more cormorants dispersed from YI, whereas cormorants on FB demonstrated greater fidelity during the nestling, fledgling, and post-breeding periods (Fig. 2).

Comparisons of radio-marked cormorants that established residency on the nesting colonies demonstrated similar colony fidelity at the managed and unmanaged sites $\left(F_{1,65}=1.23\right.$, $P=0.272)$ and between years $\left(F_{1,65}=2.52, P=0.117\right)$, but colony fidelity declined $\left(F_{3,174}=39.00, P<0.001\right)$ from the

Table 1. Fate of double-crested cormorants marked with very high frequency (VHF) transmitters nesting on Young Island, Vermont and Four Brothers Islands, New York during an experiment to determine effects of management on nesting colony fidelity in 2005 and 2006.

\begin{tabular}{llcc}
\hline & & \multicolumn{2}{c}{ Year } \\
\cline { 3 - 4 } Island & \multicolumn{1}{c}{ Fate } & $\mathbf{2 0 0 5}$ & $\mathbf{2 0 0 6}$ \\
\hline Young & Dispersed $^{\mathrm{a}}$ & 9 & 5 \\
& Culled $^{\mathrm{b}}$ & 3 & 3 \\
Four Brothers & Dead $^{\mathrm{c}}$ & 0 & 3 \\
& Dispersed $^{\mathrm{a}}$ & 18 & 16 \\
& Culled $^{\mathrm{b}}$ & 0 & 0 \\
& Dead $^{\mathrm{c}}$ & 0 & 3 \\
\hline
\end{tabular}

${ }^{a}$ After VHF transmitter attachment bird dispersed from Lake Champlain.

${ }^{\mathrm{b}}$ Shot during culling events.

${ }^{\mathrm{c}}$ Cormorant found dead of unknown cause. incubation period to the post-breeding period (Fig. 3). The effects of management and year did not interact $\left(F_{1,65}=0.00\right.$, $P=0.971)$, nor did the effects of year and period during the breeding season $\left(F_{3,174}=1.23, P=0.299\right)$. However, there was a management by period interaction $\left(F_{3,174}=6.48\right.$, $P<0.001)$ and a site by year by period interaction $\left(F_{3,174}=3.08, P=0.029\right.$; Fig. 3).

From 2004 to 2008, the number of cormorant nests on YI decreased from 1,452 to zero (Table 2). From 2004 to 2007 985 cormorants were culled on YI, representing $13 \%$ of the total cormorant count and from $7-21 \%$ of nesting cormorants in a given year (Table 2). During the same period, the number of cormorants nests on FB increased from 2,340 to 3,833 (Table 2).

Number of foraging bouts ranged from 10 to 654 for each cormorant. Foraging bout duration differed by year $\left(F_{1,154}=17.77 ; \quad P<0.001\right)$ and site $\left(F_{1,154}=27.23\right.$; $P<0.001)$, with an interaction $\left(F_{1,154}=8.78\right.$; $P=0.004)$. In 2005 , foraging bout duration was greater at $\mathrm{FB}$ than at $\mathrm{YI}(\bar{x}=59.3 \mathrm{~min}[\mathrm{SE}=1.9]$ vs. 46.5 [1.4]; $\left.t_{154}=4.61, P<0.001\right)$. In 2006 , foraging bout duration was moderately greater at $\mathrm{FB}$ than at YI $\left(\bar{x}=48.0 \mathrm{~min}[\mathrm{SE}=1.5]\right.$ vs. $44.5[1.4] ; t_{154}=1.74$, $P=0.084)$. Foraging bout duration differed between years at $\mathrm{FB}\left(t_{154}=4.61, P<0.001\right)$ but not at $\mathrm{YI}\left(t_{154}=1.00\right.$, $P=0.320)$.

Four GPS transmitters failed prior to July 15 due to unknown causes, 2 from each capture colony, so we evaluated data on the remaining 8 marked cormorants at each colony. During incubation and nestling periods (i.e., 1 May to $15 \mathrm{Jul}$ ) each year 2005-2006, we found cormorants originally marked on YI roosting primarily on YI and sites other than $\mathrm{FB}$ and MQNWR, whereas cormorants marked on FB night-roosted more often on other sites than on FB and YI (Table 3). We found cormorants originally marked on YI night-roosting for as many as 15 nights $(\bar{x}=6.5)$ on FB (Table 3), whereas we found cormorants from FB nightroosting as many as 30 nights $(\bar{x}=8.6)$ on YI (Table 3). Two (25\%) cormorants originally marked on YI had night-roost locations at MQNWR, and $5(63 \%)$ cormorants originally marked on FB had locations at MQNWR. Night use of MQNWR averaged $<1.5$ nights for cormorants marked at YI and 3 nights for cormorants marked from FB (Table 3). Interchange among night roost locations of cormorants marked from each breeding colony also included many areas outside of the 2 breeding colonies and MQNWR, but within Lake Champlain (Fig. 4). Of areas outside Lake Champlain, 2 cormorants (25\%) marked from FB had night locations on the St. Lawrence River at Lac Saint-Peirre, Quebec, Canada, and $2(25 \%)$ cormorants marked on YI had night locations at Lac Saint-Louis, Quebec, Canada.

\section{DISCUSSION}

Based on foraging bout duration, foraging habitat quality appeared to be better at $\mathrm{YI}$ than at FB, consistent with the findings of Duerr (2007). Despite greater habitat quality, the combination of egg oiling and culling (management) successfully reduced and eventually eliminated cormorant nest- 

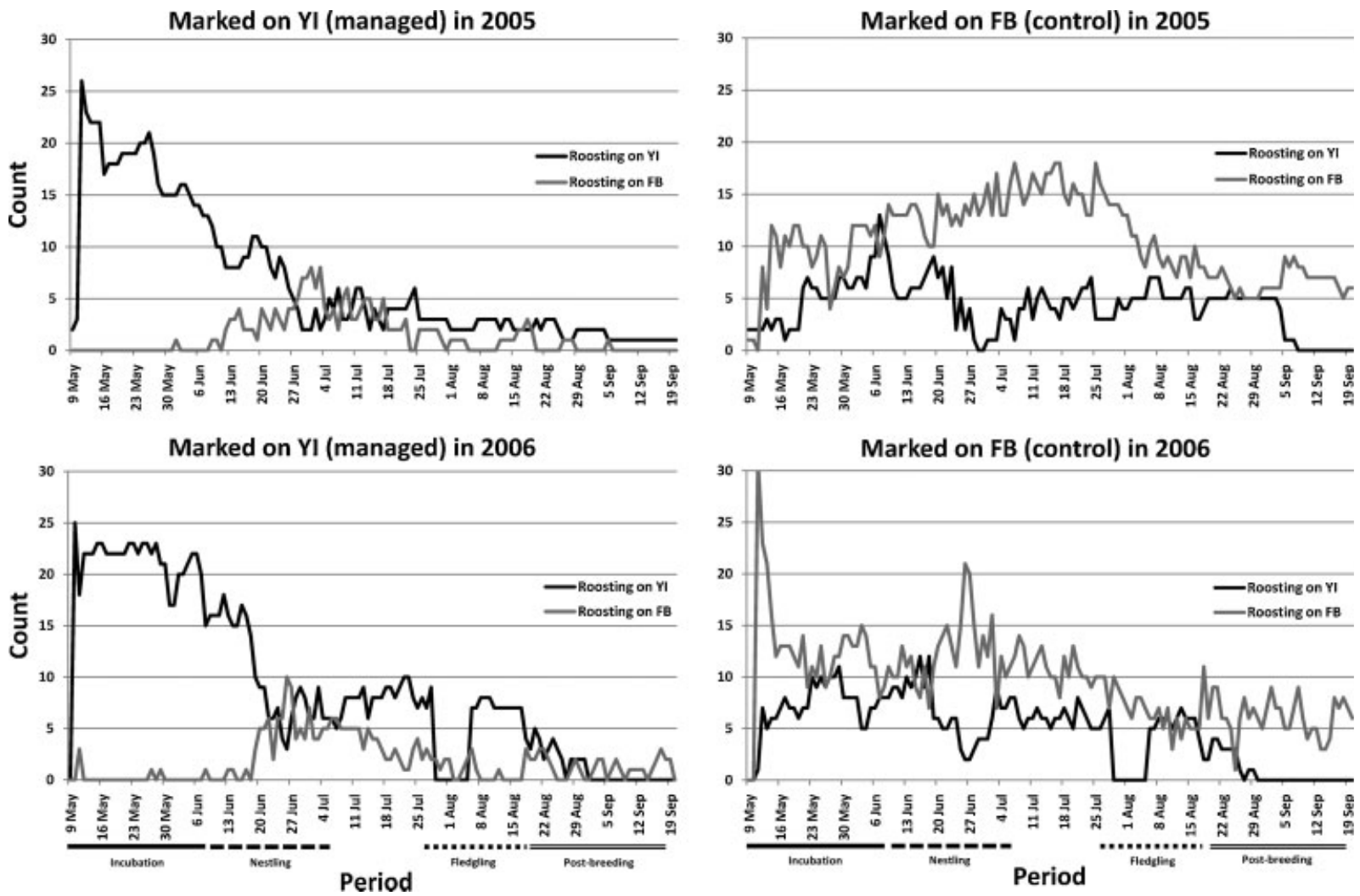

Figure 2. Number of double-crested cormorants marked with very high frequency (VHF) transmitters recorded during nighttime (0000-0500 hr) at the Young Island, Vermont (YI; managed) and Four Brothers Islands, New York (FB; control) nesting colonies in 2005 and 2006. Each panel represents the number of cormorants VHF-marked on YI in $2005(n=30)$ and $2006(n=30)$ and on FB in $2005(n=30)$ and $2006(n=33)$ present on YI or FB each night from 9 May to 19 September.

ing on YI. Although the total number of cormorants culled was $<50 \%$ of the 2004 count of adult breeding cormorants on YI, the nesting population was effectively eliminated in 4 years. These results are similar to those reported by Bédard et al. (1995), in that targeted population goals were met or exceeded sooner than expected if assuming strong philopatry

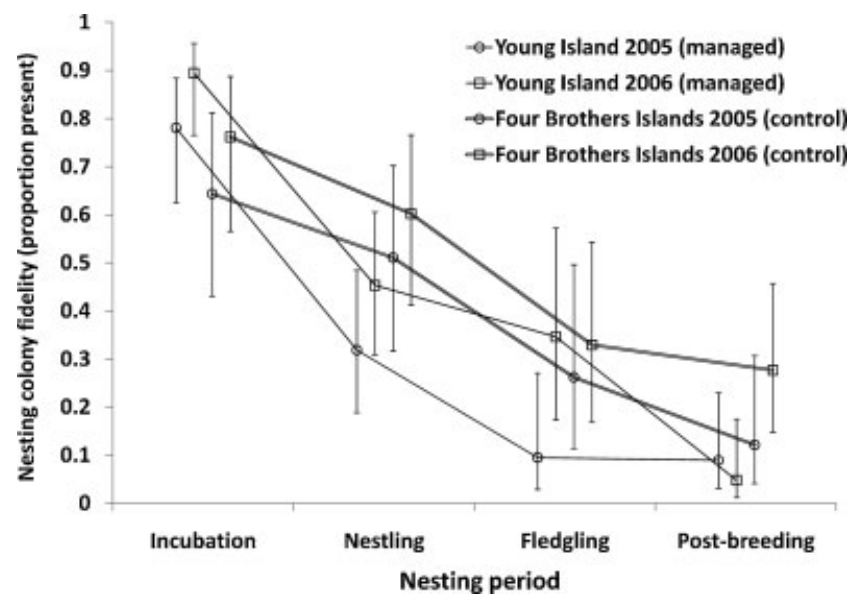

Figure 3. Effects of egg oiling and culling on fidelity of double-crested cormorants nesting on Young Island, Vermont (managed) and Four Brothers Islands, New York (control). Markers and lines represent change in mean proportion (error bars represent upper and lower $95 \% \mathrm{CIs}$ ) of cormorants present on island of capture in 2005 and 2006. to colony location and equivalent immigration and emigration (Hatch and Weseloh 1999).

The rapid decline of nesting on YI may have been influenced by male-biased culling (62\% male; B. S. Dorr, USDA National Wildlife Research Center, unpublished data). We believe culling unintentionally targets males rather than females because males are more apt to return to the island after flushing during the culling event, which is not surprising if males are defending nesting resources (Hatch and Weseloh 1999). Bédard et al. (1999) proposed disproportional culling of males (67\% male) may have been responsible for the rapid population reduction in their study. This pattern of rapid colony decline may be explained by the tendency of males to demonstrate greater inter-annual breeding site fidelity. Schjørring et al. (2000), Greenwood (1980), and Aebischer et al. (1995) all reported greater breeding site fidelity for males. If male cormorants are continually culled

Table 2. Double-crested cormorant nest counts and number of adults culled on Young Island, Vermont and Four Brothers Islands, New York during an experiment to determine effects of management on nesting colony fidelity, 2004-2008.

\begin{tabular}{llrrrrr}
\hline & & \multicolumn{5}{c}{ Year } \\
\cline { 3 - 7 } Island & Measurement & $\mathbf{2 0 0 4}$ & $\mathbf{2 0 0 5}$ & $\mathbf{2 0 0 6}$ & $\mathbf{2 0 0 7}$ & $\mathbf{2 0 0 8}$ \\
\hline \multirow{2}{*}{ Young } & Nest count & 1,452 & 1,102 & 610 & 529 & 0 \\
\multirow{2}{*}{ Four Brothers } & Birds culled & 374 & 146 & 244 & 221 & \\
& Nest count & 2,340 & 2,971 & 3,499 & 3,440 & 3,833 \\
\hline
\end{tabular}


Table 3. Night-roosting (2200-0400 hr) locations between 1 May and 15 July of double-crested cormorants marked with Global Positioning System transmitters on Young Island (managed) and Four Brothers Islands (control) in 2005 and 2006. Number on site represents the number of marked cormorants that night-roosted $\geq 1$ night at the indicated location. $\bar{x}$ nights on site $=$ mean number of nights cormorants marked at a specific nesting colony spent on the capture site and other locations.

\begin{tabular}{|c|c|c|c|c|c|c|c|}
\hline Capture site & $n$ & Night roosting locations & No. on sites (\%) & $\bar{x}$ nights on site & SE & Min. & Max. \\
\hline \multirow[t]{4}{*}{ Young Island } & 8 & Young Island & $8(100)$ & 35.6 & 4.4 & 21 & 55 \\
\hline & & Four Brothers Islands & $7(88)$ & 6.5 & 2.2 & 0 & 15 \\
\hline & & Missisquoi National Wildlife Refuge & $2(25)$ & 1.4 & 1.2 & 0 & 10 \\
\hline & & Other & $7(88)$ & 23.6 & 5.5 & 0 & 45 \\
\hline \multirow[t]{4}{*}{ Four Brothers Islands } & 8 & Young Island & $6(75)$ & 8.6 & 2.5 & 0 & 30 \\
\hline & & Four Brothers Islands & $7(88)$ & 14.3 & 3.9 & 0 & 40 \\
\hline & & Missisquoi National Wildlife Refuge & $5(63)$ & 2.9 & 0.8 & 0 & 9 \\
\hline & & Other & $8(100)$ & 36.4 & 5.1 & 8 & 58 \\
\hline
\end{tabular}

disproportionately, it follows that breeding-site fidelity would decline and contribute to site abandonment. Differential culling of males on YI is not unique, as the same trend has occurred on nesting colonies in Alabama, Minnesota, and New York (Hanson et al. 2008).

Furthermore, complete reproductive failure may be a queue to males and females to select different breeding sites the following year. Schjørring et al. (2000) reported great cormorants (Phalacrocorax carbo) demonstrated greater breeding-site fidelity following reproductive success the prior year. Similarly, the rate of return to prior-year nesting sites has been related to reproductive success the previous year in bobolinks (Dolichonyx oryzivorus; Gavin and Bollinger 1988) and in American robins (Turdus migratorius) and brown thrashers (Toxostoma rufum; Haas 1998). Reproductive failure from egg oiling was associated with greater inter-annual breeding-site dispersal rates on $\mathrm{YI}$ in previous years (3\%; Duerr et al. 2007), but during those years (2001-2003) only a portion of nests were oiled, and the nesting colony was always reestablished the following year. We oiled all nests and culled a portion of breeding adults. Perhaps the loss of a mate through adult culling combined

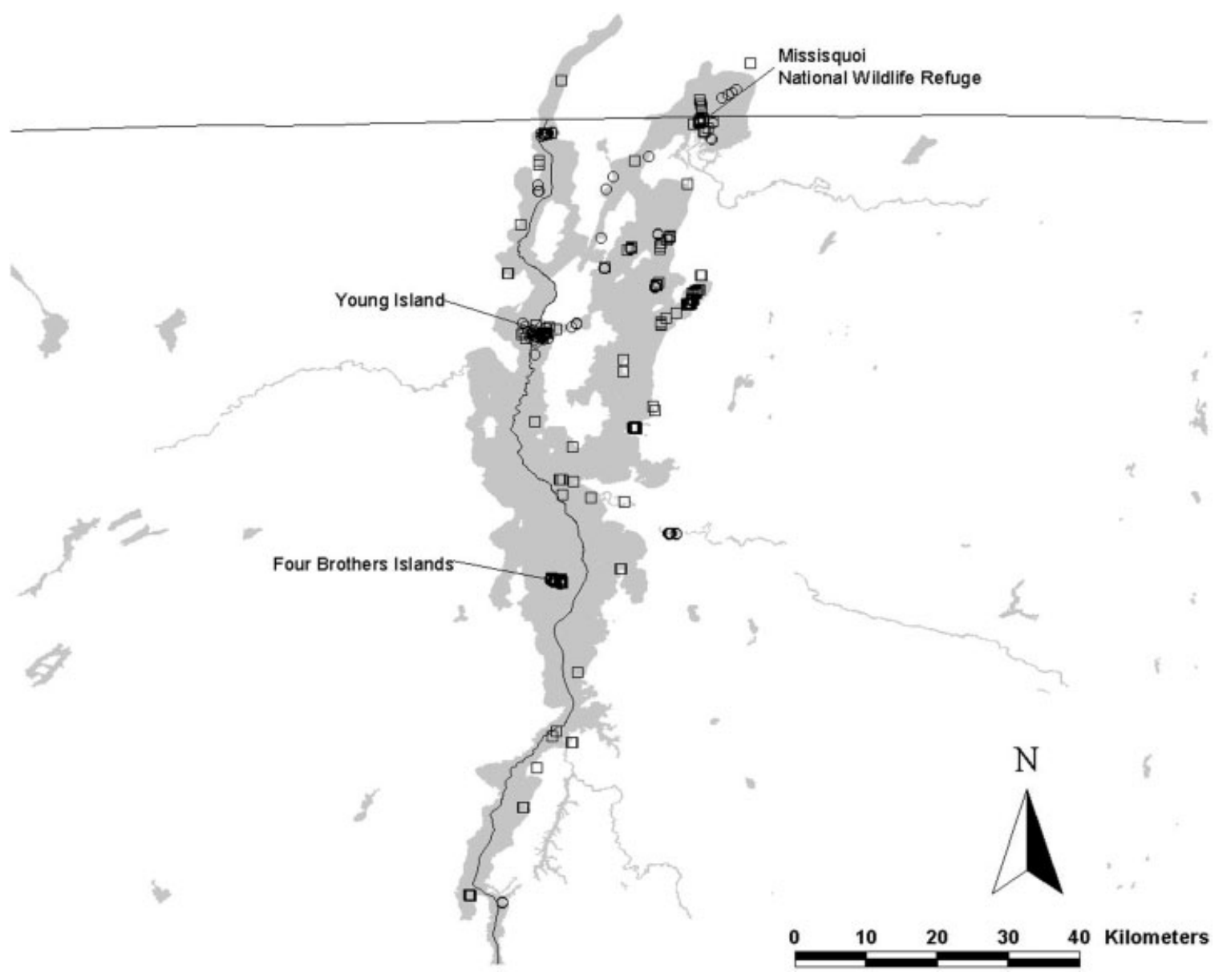

Figure 4. Night roosting (2200-0400 hr) locations of double-crested cormorants marked with Global Positioning System transmitters on Young Island ( $n=8$; open circles) and Four Brothers Island ( $n=8$; open squares) Lake Champlain, Vermont, 1 May-15 July, 2005 and 2006. 
with complete reproductive failure from egg oiling was needed to cause complete breeding-site abandonment.

We did not find an overall treatment effect of management on colony fidelity within years, but a treatment by nesting period interaction did occur, implying treatment differences occurred for different periods but not when pooled. Duerr et al. (2007) reported egg oiling increased subsequent-year dispersal of YI cormorants to FB by $20 \%$ when gulls depredated cormorant eggs during egg oiling, but the dispersal rate declined to $3 \%$ when no egg predation occurred. We oiled eggs and captured cormorants at night on YI to minimize gull depredation of cormorant eggs and dispersal of adults. Interestingly, during the incubation period cormorants radio-marked on YI exhibited greater fidelity than cormorants radio-marked on FB (Fig. 3). However, during the nestling period the opposite trend occurred, with greater dispersal occurring among YI cormorants (Fig. 3). Unfortunately, we were not able to monitor subsequent-year fidelity to nesting colonies for various reasons, including transmitter failure, radio-attachment failure, or the return of cormorants to colonies other than $\mathrm{YI}$ or FB where we could not record their presence.

Greater within-year fidelity of YI cormorants during the incubation period may have occurred due to better foraging habitat quality surrounding YI. Duerr et al. (2007) suggested the optimal time for prospecting would be at the end of the nestling phase. Accordingly, the decline of YI cormorant fidelity during the nestling period may have been caused by adults sensing reproductive failure and then prospecting for new breeding sites. If reproductive success of conspecifics is a cue for dispersal, as suggested by Boulinier et al. (1996), Schjørring et al. (2000), and Frederiksen and Bregnballe (2001), the increase of nesting colony size at FB during our study (Table 2) is logical.

We agree with Duerr et al. (2007) that managing only one nesting colony may cause dispersal to other sites. Indeed, partial egg oiling of a nesting colony may reduce dispersal by minimizing effects of prospecting and create an ecological trap for resident cormorants. However, if habitat quality is greater at a particular site, we surmise the accumulation of immigrants in subsequent years may maintain colony size or require more years (beyond the temporal threshold of stakeholders) to reduce cormorant numbers to a desired colony size. Reducing cormorant colony numbers without causing dispersal to other locations within a watershed or region would be the best management solution but may be difficult to achieve. If stakeholders desire reduction or elimination of cormorants nesting at a site or local area, then site-specific management will be required. Regrettably, such management will likely cause cormorant dispersal to other locations, but cormorants on Lake Champlain appear to disperse to other colonies even without management.

Factors other than management may also affect breeding numbers of cormorants on YI and FB. Annual re-colonization of nesting sites on Lake Champlain may be influenced by habitat quality. Duerr (2007) indicated yellow perch (Perca flavescens) comprised the bulk of cormorants' diets and that foraging habitat for this littoral species was better near YI. Evidence from other lakes indicates the recent invasion of non-native alewives (Alosa pseudoharengus) in Lake Champlain may change fish community structure in the lake (Fisheries Technical Committee 2009). Shifts in fish community structure and prey abundance and location could alter the surrounding foraging habitat quality of $\mathrm{YI}$ and FB.

Although alewives may contribute to dispersal to colonies where foraging habitat is better, presence of alewives is not likely to cause a decline in cormorant populations. Alewife have a higher energy density than most cormorant prey (Cummins and Wuycheck 1971, Seefelt and Gillingham 2008), and their size and life history have been proposed as reasons why cormorants rely on alewife as a major prey item wherever the 2 species co-exist (Weseloh and Ewins 1994, Seefelt and Gillingham 2008). Due to these factors, increase in alewives in the Great Lakes has been proposed as a mechanism facilitating the increase of cormorants in the region by enhancing reproductive success (Weseloh and Ewins 1994).

Satellite telemetry data corroborated VHF data in that there was considerable interchange of cormorants between FB and YI. Furthermore, satellite data confirmed that cormorants from both colonies moved and night roosted throughout Lake Champlain during all nesting periods (Fig. 4). The GPS-marked cormorants also moved beyond Lake Champlain within a breeding season. Most notably, 2 (25\%) cormorants originally marked on FB and 2 (25\%) cormorants marked on YI were subsequently located on the St. Lawrence River. Both FB-marked cormorants were located on Lac Saint-Pierre. It is unlikely management caused dispersal outside the Lake Champlain region because no clear colony-specific pattern of dispersal to alternative nest sites or Lac Saint-Pierre was observed, despite abandonment of the nesting sites on YI.

\section{MANAGEMENT IMPLICATIONS}

Egg oiling combined with limited culling at cormorant nesting colonies appears to be a viable management strategy to reduce colony size or maintain the colony below some specified level. Because cormorants tend to respond to management and increase numbers at other colonies within the local population, we recommend a goal-oriented approach at the local population level rather than the individual colony. By managing the population, behavioral redistribution can be predicted and included in population management objectives, and take levels can be set to reduce the effect of anticipated dispersal at the appropriate scale. Management at the local population level instead of the colony also facilitates inclusion of stakeholders who may be impacted by offsite management in the development of management goals.

Dispersal of abundant wildlife from one site where conflicts occur to another or multiple sites where existing or new conflicts may occur (conflict proliferation) may become a significant management consideration as these conflicts become more common. Many wildlife damage management paradigms and decision models rely on non-lethal dispersal and dispersal with limited lethal re-enforcement as the 
recommended first steps in resolving these conflicts. However, in cases where local superabundance results in the potential for multiple conflicts within a landscape, population management approaches that minimize dispersal yet result in reduction of targeted conflicts may be more appropriate.

Cormorant response to egg oiling and culling likely depends on nesting habitat availability. Cormorant colonies in areas with limited nesting habitat may tolerate more management before dispersing compared to colonies with greater available nesting habitat. The effects of culling may be manifested in 2 ways. First, the immediate numerical response of removing individuals from a nesting colony, and second, removal of breeding adults may accelerate subsequent-year dispersal.

\section{ACKNOWLEDGMENTS}

We thank D. Capen and A. Duerr for their continual assistance with data collection and interpretation. T. King and S. Woodruff deserve recognition for their technical and logistical support.

\section{LITERATURE CITED}

Aebischer, N. J., G. R. Potts, and J. C. Coulson. 1995. Site and mate fidelity of Shags Phalacrocorax aristotelis at two British colonies. Ibis 137:19-28.

Anderson, C. D., D. D. Roby, and K. Collis. 2004. Foraging patterns of male and female double-crested cormorants nesting in the Columbia River estuary. Canadian Journal of Zoology 82:541-554.

Ashmole, N. P. 1963. The regulation of numbers of tropical oceanic birds. Ibis 103b:458-473.

Bédard, J., A. Nadeau, and M. Lepage. 1995. Double-crested cormorant culling in the St. Lawrence River Estuary. Waterbirds 18(Special Publication 1): 78-85.

Bédard, J., A. Nadeau, and M. Lepage. 1999. Double-crested cormorant culling in the St. Lawrence River Estuary: results of a 5-year program. Pages 147-156 in M. E. Tobin, technical coordinator. Symposium on double-crested cormorants: population status and management issues in the Midwest. USDA, Animal and Plant Health Inspection Service Technical Bulletin 1879, Washington, D.C., USA.

Birt, V. L., T. P. Birt, D. Goulet, D. K. Cairns, and W. A. Montevecchi. 1987. Ashmole's halo: direct evidence for prey depletion by a seabird. Marine Ecology Progress Series 40:205-208.

Boulinier, T., E. Danchin, J.-Y. Monnat, C. Doutrelant, and B. Cadiou. 1996. Timing of prospecting and the value of information in a colonial breeding bird. Journal of Avian Biology 27:252-256.

Cuthbert, F. J., L. R. Wires, and J. E. McKearnan. 2002. Potential impacts of nesting double-crested cormorants on great blue herons and blackcrowned night-herons in the U.S. Great Lakes region. Journal of Great Lakes Research 28:145-154.

Cummins, K. W., and J. C. Wuycheck. 1971. Caloric equivalents for investigations in ecological energetics. International Association of Theoretical and Applied Limnology 18:1-51.

Daniel, A. 1989. Forest decline on Young Island: impact of nesting ringbilled gulls on vegetation and soils with recommendations for wildlife management. Thesis, University of Vermont, Burlington, USA.

Duerr, A. E. 2007. Population dynamics, foraging ecology, and optimal management of double-crested cormorants on Lake Champlain. Dissertation, University of Vermont, Burlington, USA.

Duerr, A. E., T. M. Donovan, and D. E. Capen. 2007. Managementinduced reproductive failure and breeding dispersal in double-crested cormorants on Lake Champlain. Journal of Wildlife Management 71:2565-2574.

Dunstan, T. C. 1972. A harness technique for radio-tagging raptorial birds. Inland Bird Banding News 44:4-8.

Fielder, D. G. 2008. Examination of factors contributing to the decline of the yellow perch population and fishery in Les Cheneaux Islands, Lake
Huron with emphasis on the role of double-crested cormorants. Journal of Great Lakes Research 34:506-523.

Fisheries Technical Committee. 2009. Strategic plan for Lake Champlain fisheries. Lake Champlain Fish and Wildlife Management Cooperative, United States Fish and Wildlife Service, Essex Junction, VT. <http:// www.dec.ny.gov/docs/regions_pdf/09lcfishplan.pdf $>$. Accessed $11 \mathrm{Feb}$ 2011.

Fowle, M. R., D. E. Capen, and N. J. Buckley. 1999. Population growth of double-crested cormorants in Lake Champlain. Northeast Wildlife 54: 25-33.

Frederiksen, M., and T. Bregnballe. 2001. Conspecific reproductive success affects age of recruitment in a great cormorant, Phalacrocorax carbo sinensis, colony. Proceedings of the Royal Society of London, Series B 268:1519-1526.

Gavin, T. A., and E. K. Bollinger. 1988. Reproductive correlates of breeding-site fidelity in Bobolinks (Dolichonyx oryzivorus). Ecology 69:96-103.

Glahn, J. F., and K. E. Brugger. 1995. The impact of double-crested cormorants on the Mississippi delta catfish industry: a bioenergetics model. Colonial Waterbirds 18(Special Publication 1): 168-175.

Glahn, J. F., M. E. Tobin, and B. F. Blackwell. 2000. A science-based initiative to manage double-crested cormorant damage to southern aquaculture. USDA, Animal Plant and Health Inspection Service, Publication 11-55-010, Washington, D.C., USA.

Glahn, J. F., S. J. Werner, T. Hanson, and C. R. Engle. 2002. Cormorant depredation losses and their prevention at catfish farms: economic considerations. Pages 138-146 in L. Clark, J. Hone, J. A. Shivik, R. A. Watkins, K. C. VerCauteren, and J. K. Yoder, editors. Human conflicts with wildlife: economic considerations. Proceedings of the Third NWRC Special Symposium. National Wildlife Research Center, Fort Collins, Colorado, USA

Greenwood, P. J. 1980. Mating systems, philopatry and dispersal in birds and mammals. Animal Behaviour 28:1140-1162.

Haas, C. A. 1998. Effects of prior nesting success on site fidelity and breeding dispersal: an experimental approach. Auk 115:929-936.

Hanson, K. C., T. L. DeVault, and S. C. Barras. 2008. Segregation of male and female double-crested cormorants in the Eastern United States. The Wildlife Society 15th Annual Conference. Miami, Florida, 8-12 Nov 2008. Published Abstract.

Hatch, J. J., and D. V. Weseloh. 1999. Double-crested cormorant (Phalacrocorax auritus). Account 441 in A. Poole and F. Gill, editors. The birds of North America. The Academy of Natural Sciences, Philadelphia, Pennsylvania, and The American Ornithologists Union, Washington, D.C., USA.

Hebert, C. E., J. Duffe, D. V. C. Weseloh, E. M. T. Senese, and G. D. Haffner. 2005. Unique island habitats may be threatened by doublecrested cormorants. Journal of Wildlife Management 69:68-76.

King, D. T., M. E. Tobin, and M. Bur. 2000. Capture and telemetry techniques for double-crested cormorants (Phalacrocorax auritus). Proceedings of the Vertebrate Pest Conference 19:54-57.

Krohn, W. B., R. B. Allen, J. R. Moring, and A. E. Hutchinson. 1995. Double-crested cormorants in New England: population and management histories. Waterbirds 18(Special Publication 1): 99-109.

Lewis, S., T. N. Sheratt, K. C. Hamer, and S. Wanless. 2001. Evidence of intra-specific competition for food in a pelagic seabird. Nature 412:816819.

Lemmon, C. R., G. Bugbee, and G. R. Stephens. 1994. Tree damage by nesting double-crested cormorants in Connecticut. Connecticut Warbler 14:27-30.

Littell, R. C., G. A. Milliken, W. W. Stroup, R. D. Wolfinger, and O. Schabenverger. 2006. SAS for mixed models. Second edition. SAS Institute, Inc., Cary, North Carolina, USA.

Ridgeway, M. S., J. B. Polard, and D. V. C. Weseloh. 2006. Densitydependent growth of double-crested cormorant colonies on Lake Huron. Canadian Journal of Zoology 84:1409-1420.

Rudstam, L. G., A. J. VanDeValk, C. M. Adams, J. T. H. Coleman, J. L. Forney, and M. E. Richmond. 2004. Double-crested cormorant predation and the population dynamics of walleye and yellow perch in Oneida Lake. Ecological Applications 14:149-163.

Schjørring, S., J. Gregersen, and T. Bregnballe. 2000. Sex difference in criteria determining fidelity towards breeding sites in the great cormorant. Journal of Animal Ecology 69:214-223. 
Seefelt, N. E., and J. C. Gillingham. 2008. Bioenergetics and prey consumption of breeding double-crested cormorants in the beaver archipelago, Northern Lake Michigan. Journal of Great Lakes Research 34:122-133.

Shonk, K. A., S. D. Kevan, and D. V. Weseloh. 2004. The effect of oil spraying on eggs of double-crested cormorants. Environmentalist 24:119124.

United States Fish and Wildlife Service. 2003. Final rule and notice of record of decision: regulations for double-crested cormorant management. Federal Register 50 CFR Part 21 68:58022-58037. <http://www.fws.gov/ migratorybirds/CurrentBirdIssues/Management/cormorant/FinalRule/ fed1regdccofinalrule.pdf $>$. Accessed 3 Feb 2011.

VanDeValk, A. J., C. M. Adams, L. G. Rudstam, J. L. Forney, T. E. Brooking, M. Gerken, B. Young, and J. Hooper. 2002. Comparison of angler and cormorant harvest of walleye and yellow perch in Oneida Lake, New York. Transactions of the American Fisheries Society 131:27-39.
Weseloh, D. V., and P. J. Ewins. 1994. Characteristics of a rapidly increasing colony of double-crested cormorants (Phalacrocorax auritus) in Lake Ontario: population size, reproductive parameters and band recoveries. Journal of Great Lakes Research 20:443-456.

Weseloh, D. V., P. J. Ewins, J. Struger, P. Mineau, C. A. Bishop, S. Postupalsky, and J. P. Ludwig. 1995. Double-crested cormorants of the great lakes: changes in population size, breeding distribution and reproductive output between 1913 and 1991. Waterbirds 18(Special Publication 1): 48-59.

Wywialowski, A. P. 1999. Wildlife-caused losses for producers of channel catfish (Ictalurus punctatus) in 1996. Journal of the World Aquaculture Society 30:461-472.

Associate Editor: Michael Eichholz. 